\title{
Computational Thinking Education in the Asian Pacific Region
}

\author{
Hyo-Jeong So ${ }^{1} \cdot$ Morris Siu-Yung Jong ${ }^{2} \cdot$ Chen-Chung Liu ${ }^{3}$
}

Published online: 18 December 2019

(C) De La Salle University 2019

\begin{abstract}
The importance of computational thinking (CT) education in the twenty-first century cannot be understated, as digital computing technologies have become an essential component of practically all human activities. Due to their strength in the ICT industry, countries such as Korea, Taiwan, Hong Kong, and China have launched national curricular reforms to address the current movement of CT education in K-12 education. This special issue, therefore, intends to provide insights into the current curricular reform movement of CT education in the Asian Pacific region. It includes six papers presenting studies which expose the recent evidence-driven research and development of CT education. The findings of the studies shed light on the future policy and implementation of CT education in the Asian Pacific region. Integrating CT into formal education involves far more than learning and teaching of computational concepts and coding skills. We hope that this special issue provides better understandings of the current status of CT education in the Asia-Pacific region and the challenges faced by teachers, school administrators, and policy makers as well as other key stakeholders in the education community.
\end{abstract}

Chen-Chung Liu

ccliu@cl.ncu.edu.tw

1 Department of Educational Technology, Ewha Womans University, Seoul, Korea

2 Department of Curriculum and Instruction, The Chinese University of Hong Kong, Hong Kong, China

3 Department of Computer Science and Information Engineering, Graduate Institute of Network Learning Technology, National Central University, Jhongli City, Taiwan (ROC)
Keywords Computational thinking · Coding · Asian Pacific region

\section{Introduction}

The term "computational thinking" (CT) is first mentioned by Wing (2006). According to Wing's definition, CT involves "solving problems, designing systems, and understanding human behaviors, by drawing on the concepts fundamental to computer science" (p. 33). From such a perspective, $\mathrm{CT}$ is more than just coding. It represents a more than a skill to be able to program, but also the skills to process information and the attitude that computer scientists generally hold to solve problems. More specifically, CT involves several imperative thinking skills including abstraction and decomposition, thinking recursively, problem reduction and transformation, error prevention and protection, and heuristic reasoning which are needed to solve universal complex problems, not limited to software problems. Therefore, CT represents a universal skill set that everyone from different disciplines, not only computer scientists, should learn.

The importance of CT education in the twenty-first century cannot be understated, as digital computing technologies have become an essential component of practically all human activities. National security, economics, public health, and safety, for example, are key areas that currently and increasingly rely on advances in digital technologies, making it unsurprising that governments around the world have begun to prioritize computer science education for current and future generations of students. In the US, the International Society for Technology in Education (ISTE) and Computer Science Teachers Association (CSTA) (2014) provide plenty of resources for "CT in 
K-12 Education" (e.g., teacher resources, CT workshops, and relevant academic activities). In Europe, a survey conducted by Ministries of Education revealed that 13 countries aim to develop students' logical thinking skills and problem-solving skills through CT (Mannila et al. 2014). In Asian countries/systems, CT becomes an emerging issue from research, pedagogical practices, and policies (Wong et al. 2015). Due to their strength in the ICT industry, countries such as Korea, Taiwan, Hong Kong, and China have launched national curricular reforms to address the current movement in CT education.

In Korea, although CT education is still in its early stages of the nationwide implementation, there has been some research evidence supporting the efficacy of learning coding skills and related CT skills. In K-12 contexts, CT education in Korea has been conducted in the areas of (a) innovating pedagogical approaches specific to $\mathrm{CT}$, (b) developing assessment tools to measure students' CT knowledge, skills, and attitudes, (c) expanding coding education with physical computing and makers education, and (d) training teachers' CT skills and their perceptions about the efficacy of coding education (e.g., Choi and Kim 2017; Jun et al. 2014; Lee and Lee 2015; Shin 2015). A large-scale research reveals that students, teachers, and parents have overall positive perceptions about the needs and efficacy of software education in schools (Lee et al. 2016). To date, CT research for university students has received relatively less attention than that for K-12 students. Recently, there has been increasing attention as to how to teach coding skills to university students with noncomputer science backgrounds (Nah 2017). The emphasis on coding education comes from the initiatives that several universities in Korea have taken to restructure and redesign courses to accommodate needs for developing student competencies in creative and convergent skills.

In Taiwan, a new curriculum for CT education has been launched in 2019 to foster citizens' learning and working skills that are needed in the twenty-first century. The new curriculum intends to (a) develop CT skills, (b) build literacies of using information technologies for collaboration and communication, and (c) foster appropriate attitude on using information technologies (Ministry of Education, Taiwan 2016). The curriculum explicitly outlines the integral components of CT that must be included in the school curriculum. Topics include both primitive CT concepts such as arrays and iterations and advanced concepts including trees and graphs. The curriculum will be implemented in each school at least $1 \mathrm{~h}$ from grades 7 to 9 and $2 \mathrm{~h}$ from grades 10 to 12 on a weekly basis.

In Hong Kong, CT is mainly cultivated through coding education. CT is considered as an essential problem-solving skill in today's society with rapid technological development. CT education has been immersed in a diversity of school subjects in Hong Kong. For instance, "CoolThink@JC" is an educational project focusing on the primary students' CT cultivation, which includes a framework for guiding the design of K-12 CT curriculum (Kong 2016). The results of earlier studies on coding education in a Hong Kong local primary school from 2012 to 2014 indicated a positive impact on the overall performance of mathematics and general studies subjects (Wong et al. 2015). However, practical challenges such as a lack of teacher training and unified curriculum need to be addressed when CT education is implemented in formal education (Wong et al. 2016).

On the whole, the current curricular reform movement of CT in the Asian Pacific region expands to cover K-12 students. Due to the complex nature of CT, current enthusiasm toward CT education may not lead to positive outcomes, if policies and implementation methods are not formed with appropriate considerations of the unique culture in the region. The questions such as at what age children should start to learn CT skills, how CT should be integrated with existing curricula, what is the impact of the early CT education on students' cognitive development and their influence on motivation, should be examined through theoretically and methodologically rigorous approaches. This special issue, therefore, intends to provide insight into the current curricular reform movement of CT education in the Asian Pacific region.

\section{The Development of Computational Thinking Education}

\section{Theoretical Analysis of CT Notion}

CT is not a new notion but has existed for several decades. What constitutes CT, however, has been undergoing several debates and re-examinations to encompass several core competencies. While no clear consensus on the definition has reached, there are core elements of CT widely accepted across diverse definitions such as abstractions and pattern generalizations, systematic processing of information, symbol systems and representations, and algorithmic notions of the flow of control (Grover and Pea 2013). In 2011, ISTE and CSTA developed an operational definition of $\mathrm{CT}$ and provided a framework for $\mathrm{K}-12$ educators. After some years of implementation in schools, a "step-by-step cognitive strategy" for teaching computer programming with CT in secondary schools (Brannon 2016) was proposed.

Despite the government policies toward supporting CT education in the Asian Pacific region, there have been several issues and tensions created in both the public sector and the research community. One of the core tensions is the 
narrow conception of CT (merely coding skills), and the lack of curriculum hours allocated to CT education. Due to the different conception of CT, countries allocated different curriculum hours for $\mathrm{CT}$ education. Therefore, a clear structure of CT is necessary to guide the CT education policy and implementation scheme. Concerning the inherent tension in attempting to define CT, Voogt et al. (2015) argue that it is more productive to identify core qualities versus peripheral qualities, rather than to draw a single definition. The relevant learning theories (e.g., constructivism), the definitions and key conceptual constructs, and relevant pedagogical approaches (e.g., problem-solving) of CT education will be helpful for the countries in the Asian Pacific region to set up and adjust their national curricula for CT education.

\section{The Impact of Formal CT Education on Motivation}

CT will be shifted from informal learning to formal learning, meaning that all students have to participate in the formal program in school. Thus, the assessment needs to be performed for each student in order to evaluate his/her performances in the formal education system. Several issues may arise due to such a dramatic change. First, student motivation on CT may be significantly impacted. Students in Asian countries including China, Hong Kong, Japan, Korea, Singapore, and Taiwan are leading in international STEM assessments such as TIMSS and PISA (Marginson et al. 2013). However, it is also reported that student motivation in STEM-related subjects is surprisingly lower than the average (Liou 2014). Some studies indicated that the Confucian Heritage Culture coupled with the belief that effort rather than ability is the primary source of success may be able to explain both high achievement and high anxiety among Asian students (Morony et al. 2013). As CT becomes a mandatory subject in the formal education system, it is necessary to explore whether the implementation of the curriculum has a significant impact on students' motivations in Asian countries.

\section{Pedagogy for Cultivating CT}

The shift of CT education from an informal setting to formal one may also have a direct impact on the pedagogies that teachers use to develop students' CT skills. In the past when CT was not included in the national curriculum, many active learning pedagogies such as gamebased learning (Liu et al. 2011) and constructivist approaches (Barnes et al. 2007; Kafai 2016) were extensively implemented in informal learning settings (e.g., student clubs) as teachers did not have the pressure on students' performances. It is possible that didactic approaches may dominate the implementation of CT education when $\mathrm{CT}$ is included in the national curriculum due to the credentialism and the time constraint in curricula hours. It is thus necessary to explore how the curricular shift may change the pedagogies that teachers use in formal learning settings. Furthermore, the pedagogies that teachers apply in schools may have a direct influence on students' conception of CT skills. In the literature, there exists a significant difference in the teachers' and students' conception of STEM learning among different Asian countries due to the cultural difference (Lee et al. 2012; Lin et al. 2013). Timely investigations become critical to understand how the shift of CT education may change students' skills and their conception of $\mathrm{CT}$ in different countries in the Asian Pacific Region.

\section{Assessing CT}

The curricular reform in CT inevitably affects other research activities, such as how to assess CT and what should be included in the curriculum as core competencies. In particular, how to assess computational concepts, attitudes and practices remains a challenge. Some scholars have developed the instruments and scales that operationally define the core constructs of CT (e.g., RománGonzález et al. 2016). Recently, new perspectives to assess CT have emerged. For instance, Grover (2015) proposes the idea of systems of instrument from the "Preparation of Future Learning" (PFL) perspective that intends to assess the growth of algorithmic thinking skills and transfer of these skills. Some researchers proposed frameworks and methods to evaluate multiple aspects of CT (e.g., Brennan and Resnick 2012; Lye and Koh 2014). There are also numbers of methods to evaluate CT outcomes, including Fairy Performance Assessment (Werner et al. 2012), Computer game-based Coding Category Method (Denner et al. 2012), Digital Ink for Cognitive Assessment (Ambrósio et al. 2014) and Bebras test (Dagiene and Stupuriene 2016). More research attempts are needed to develop holistic ways of assessing CT practices and attitudes as CT is more than a composition of discrete competencies and the understanding of abstract concepts. This line of research will help teachers to obtain both descriptive and prescriptive information to make pedagogical decisions.

\section{Positioning CT in the Formal Curriculum}

Despite this renewed interest in CT, there is a range of issues and challenges as we attempt to integrate $\mathrm{CT}$ in the formal curriculum in K-12 settings. As computational thinking has been introduced as the part of the school curriculum, many issues such as the lack of rationale for making it a mandatory subject, and the lack of 
pedagogically relevant teaching and learning materials have appeared around the multiple interpretations of core components (Grover and Pea 2013). In some countries, the mandate of CT education in the school curriculum has generated the public concern and parental burden regarding the rise of after-school cram schools and private education for teaching coding skills. This phenomenon creates potential problems such as increasing spending on private education, inequality in educational opportunities and unhealthy competitions, which are great deviations from the rationale of integrating CT education in schools (Park 2016).

In the study by Gal-Ezer and Stephenson (2014), they pointed out that there is a lack of common understandings of CT and whether teachers have the technical, content, and pedagogical knowledge needed to teach $\mathrm{CT}$ is also a challenge to implement CT programs in K-12 classes. Another debatable issue is whether CT should be positioned as a separate subject or cross-curricular practice, which has immediate implications on how the qualifications and training of teachers teaching CT in school should be defined (Voogt et al. 2015). Most of the current pedagogical use of CT is in the computer science subject. Programming and coding classes are the major forms to achieve. However, the systematic curriculum development and relevant applications/integrations of $\mathrm{CT}$ in practices still need further exploration. Moreover, relevant professional development programs for teachers and teachers' adaptations on CT-relevant teaching and learning activities are important issues to discuss in-depth.

\section{CT and Participation}

The research community of CT is entering the new and exciting stage with the increasing possibilities of promoting CT through emergent technologies such as visual and tangible programming experiences. Furthermore, beyond the formal learning sphere, there are abundant informal learning activities happening such as the Makerspace movement, hacker events, and the Scratch community where the youth can collaborate and co-construct computational objects and shareable applications. The changing environment offers the possibility of extending the traditional notion and elements of CT to embrace other digital activities in informal learning spaces. Corroborating such new perspectives and possibilities, Kafai (2016) argues for the need to reframe CT as computational participation, which emphasizes the social and creative nature of computational practices. Clearly, CT education is no longer a solitary activity, but a social practice that allows participation in other digital collaborative activities. However, computational thinking and participation in informal learning spaces are under-investigated, and we have little knowledge of how and under what conditions such participatory and voluntary activities can be fostered and sustained.

\section{The Special Issue}

Particularly in the Asia-Pacific region where the government, education, and economic development landscape is complex and rapidly changing, it is important to understand how CT tools and practices are currently used in classrooms and how the government policies and initiatives have been supporting CT education. The trajectory of CT education in the region highlights that $\mathrm{CT}$ research in the Asian context needs to consider the complex multi-faceted factors within and outside the education systems such as gaining parental supports, teachers' buy-ins, redesigning teacher preparation programs, and changing assessment approaches. This special issue includes six papers presenting studies aiming to expose the recent evidence-driven research findings and development in implementing CT education that may shed light on the policy and implementation of CT education in the Asian Pacific region.

The study by Tang, Chou and Tsai of this special issue conducted a keyword analysis about the CT education studies published from 2006 to 2018. The study demonstrated not only the current trend in this field but a novel literature analysis technique. Instead of applying traditional content analysis, this study applied the data mining technique to analyze the trends of keywords that appear in the papers. Such an approach can reveal the characteristics of the research studies in the field and is beneficial for researchers to gain a better understanding of this field (Liu et al. 2010). The analysis identified several interesting research trends in the field of CT research. Games, collaborative learning, and simulations are the most frequently adopted pedagogies in the literature. Scratch, robots, Lego, and Alice were found to be extensively and increasingly used in CT research in recent years. The findings reflect that game-based learning and constructivist approaches are still the main research topics in the field of CT education.

To understand teachers' readiness in implementing CT education, the study by $\mathrm{Wu}$ et al. conducted an international study between five education systems (Mainland China, Finland, South Korea, Singapore and Taiwan). An assessment framework based on TPCK-W and The Technology and Internet Assessment (TIA) was developed to investigate teachers' competency in implementing CT education. The study found that teachers overall considered that coding is learned best by writing codes with visual programming. Interestingly, there is a significant discrepancy in the way to learn coding through writing codes between these education systems. While the majority of 
teachers in Mainland China thought that coding is best learned under teachers' guidance, the teachers in Finland, South Korea, and Singapore disagreed with this assertion. Furthermore, the majority of teachers in Mainland China and Taiwan considered that coding is best learned from books and dedicated websites while the teachers in Finland, South Korea, and Singapore did not. The previous study by Chan and Elliott (2004) has indicated that cultural context has an unneglectable impact on epistemological belief, which is closely related to teachers' conception of teaching and learning. This can partially explain why teachers from different education systems indicated a discrepancy in the way to learn coding.

Researchers have been emphasizing the importance of new competencies that students need in the twenty-first century. It is commonly recognized that collaboration, problem-solving, creativity, and critical thinking are the core competencies that students should have (Van Laar et al. 2017). The study by Saritepeci asserts that CT should connect to the integral competencies of the twenty-first century, and the assessment of CT should involve the evaluation of these competencies in addition to algorithmic thinking. Based on such a perspective, a design-based learning approach was implemented through the digital storytelling activity rather than pure programming tasks. The result suggests that both the design-based learning and programming approach enhanced CT skills. However, the programming task approach demonstrated a higher level of enhancement in the dimension of critical thinking and algorithmic thinking. The results suggest that although the digital storytelling approach may engage high school students in learning about $\mathrm{CT}$, it is still necessary to provide opportunities for students to experience coding activities in order to understand the essential thinking skills in programming.

In this special issue, two articles focus on the efficacy of unplugged activities to help students develop CT concepts. In general, unplugged activities refer to a set of learning activities to introduce coding without a computer and often involve the use of physical movement and tangible materials. Unplugged activities are particularly relevant to young learners and novice learners with less technical skills. The article by Saxena, Lo, Hew and Wong examines the potential of coupling unplugged-and-plugged activities for young learners in Hong Kong to learn about CT concepts (i.e., pattern recognition, sequencing, algorithm design). This study examined the youngest participant group (11 learners aged 3-6) among six articles in this special issue. One of the debatable issues in CT research is at what age children should start to learn CT skills. While some scholars (e.g., Manches and Plowman 2017) emphasize early exposures to CT skills, there are equally valid concerns regarding whether young learners should be taught about CT skills. There is no conclusive answer to this debatable issue, mainly due to the lack of empirical research done with young learners. With that, this study by Saxena et al. makes a meaningful contribution to the existing literature by demonstrating that it is feasible for learners as young as 3-6 years old to master some basic CT concepts such as pattern recognition and sequencing through participation in the unplugged-and-plugged activities. Their intervention involves the use of Bee-bot and various unplugged activities such as LEGO pattern and sequencing stories, vocabulary building songs, and tic-tactoe, which other researchers and practitioners can easily adopt and adapt for designing CT lessons. This study also suggests the need for future research that examines how to design learning activities for introducing more complex and advanced CT concepts to young learners.

Zooming into the potential of unplugged activities, the article by Kuo and Hsu presents an interesting intervention done in Taiwan that leverages the affordances of unplugged activities, game-based learning, and peer collaboration to help students develop CT. The type of unplugged activities used in their study is a board game called "Robot City" that embeds programming structures and concepts. One notable aspect of their research design is the use of different participant structures, namely open-ended competitive participation versus structured collaborative participation. In real practices, coding is rarely a solo activity and involves collaborative problem-solving. Reflecting this authentic nature, the participant structure of their study simulates paired programming and iterative review of coding. Another strength of this study is that it examines the qualitative process of collaborative behaviors as well as quantitative measures of CT skills. The results indicate that groups in the clear-ended tasks outperformed their counterparts in the open-ended tasks. The authors attribute the better gain in the clear-ended structure group to the ease of building consensus and identifying targeted goals. The contribution of this study goes to the examination of task design issues that were less examined in the existing CT research. While open structure and competition were less effective in this study, it remains a question if similar findings would be obtained in less time-bound and efficiency-driven learning contexts.

The next article by So, Kim and Ryoo examines the issue of developing CT competencies among girls. Gender equity is one of the under-researched areas in the existing CT literature (Grover and Pea 2013). The field of science and computing is still male-dominant, and women belong to the marginalized group in STEM-related careers. However, So et al. suggest that "there is no conclusive evidence of a gender difference in CT, and if any difference exists, it shows varying patterns". Given the limited understanding of gender disparity in CT, their study examines how three 
girls in Korea developed CT competencies from their initial exposure to computers to the growth of interest and expertise in CT competencies through their childhoods. Notably, this study examines girls gifted in computer science who are rare due to gender stereotypes and sociocultural factors related to computing. By adopting the DMGT (differentiating model of giftedness and talent) 2.0 (Gagné 2013) as an analytical lens, this study unpacks the trajectory of gifted girls' CT development over time. Their key findings confirm some accepted beliefs such as the critical role that parents and teachers play, and the role of formal learning experiences. This study also reveals unexpected findings such as girls' use of rather limited learning resources and knowledge building strategies and the weak linkage between CT competencies and future career goals. This paper ends with a call for more research tackling gender issues in CT and the development of CT programs accommodating the unique needs of female leaners.

\section{Conclusions and Future Investigations}

This special issue included five empirical studies and one literature review study. These studies contributed to a better understanding of the current research trend in the field of CT education and teachers' perception, pedagogical design issues, and gender issues associated with CT education. However, several issues remain unclear and need further investigations in order to improve CT education under the policy change in Asian countries.

\section{The Conception of Leaning CT}

The study by Wu et al. (2020) has identified the discrepancy in teachers' conception of teaching and learning of CT among several countries. However, the temporal change of students' and teachers' conception of teaching and learning CT caused by the policy change is still unknown in the literature. During the past few years, several countries have included CT education in the national curricula and the teaching/learning $\mathrm{CT}$ has become one mandatory subject in school. Whether such a change in national curricula will have a negative or positive impact needs timely monitoring and systematic analysis. For instance, if the assessment of CT becomes mandatory in school, students may be more likely to consider that learning of $\mathrm{CT}$ is to pass a formal examination rather than to achieve a personal goal in learning.

\section{Helping Students Cross the Gap from Fun CT to Professional Coding}

Multiple tools including unplugged games and the digital storytelling tool were applied in the studies included in this special issue. The purposes of such pedagogical designs are to increase the fun elements and to improve students' interest in the learning of CT. However, as students are progressing to a certain cognitive level, they need to migrate to professional coding tasks. The gap between fun $\mathrm{CT}$ and professional coding is significant for many learners as professional coding involves complex syntax, implicit software dependencies, and challenging debugging tasks. Further studies are necessary to understand the pedagogical design that helps students cross the gap from fun CT to professional coding.

\section{CT in Marginalized and Under-Resourced Areas}

The Asia-Pacific region is one of the most populated region with diverse cultural and socio-economic backgrounds. Several countries in the region still face challenging issues in basic education, such as achieving universal education, gender inequity in access to education, and poor technological infrastructures. While this special issue aims to offer insights regarding the current status of CT education in the Asia-Pacific region, the contributed papers are from developed countries with considerably advanced IT infrastructure. We are still left with the missing picture of how developing countries in the Asia-Pacific region are implementing CT in their education systems and whether there are any unique challenges faced by schools, teachers, and students in marginalized and under-resourced areas. Since students in these areas are deprived of opportunities to develop CT, the gap of CT competencies between the developed and developing areas may be widening over time. This special issue, hence, calls for the need for subsequent research that reports the current status of CT education for students in marginalized and under-resourced areas.

Integrating $\mathrm{CT}$ in formal education involves far more than introducing computational concepts and coding skills. We hope that this special issue provides better understandings of the current status of CT education in the AsiaPacific region and the challenges faced by schools and key stakeholders. 


\section{References}

Ambrósio, A. P., Xavier, C., \& Georges, F. (2014). Digital ink for cognitive assessment of computational thinking. In: 2014 IEEE Frontiers in Education Conference (FIE), (pp. 1-7). IEEE.

Barnes, T., Richter, H., Powell, E., Chaffin, A., \& Godwin, A. (2007, June). Game2Learn: Building CS1 learning games for retention. ACM SIGCSE Bulletin, 39(3), 121-125.

Brannon. (2016). What is computational thinking and why is it important? Retrieved on Dec. 2017 from the Ohio Department of Education website. https://education.ohio.gov/Media/ExtraCredit-Blog/November-2016/GUEST-BLOG-What-is-Compu tational-Thinking-and-Why

Brennan, K., \& Resnick, M. (2012). New frameworks for studying and assessing the development of computational thinking. In: Proceedings of the 2012 annual meeting of the american educational research association, Vancouver, Canada (pp. $1-25)$.

Chan, K. W., \& Elliott, R. G. (2004). Relational analysis of personal epistemology and conceptions about teaching and learning. Teaching and Teacher Education, 20(8), 817-831.

Choi, H. S., \& Kim, M. S. (2017). Designing a new teacher education course for integrating design thinking with computational thinking. Journal of the Korean Association of Information Education, 21(3), 343-350.

Dagiene, V., \& Stupuriene, G. (2016). Bebras-A sustainable community building model for the concept based learning of informatics and computational thinking. Informatics in Education, 15(1), 25-44.

Denner, J., Werner, L., \& Ortiz, E. (2012). Computer games created by middle school girls: Can they be used to measure understanding of computer science concepts? Computers \& Education, 58(1), 240-249.

Gagné, F. (2013). The DMGT: Changes within, beneath, and beyond. Talent Development \& Excellence, 5(1), 5-19.

Gal-Ezer, J., \& Stephenson, C. (2014). A tale of two countries: Successes and challenges in K-12 computer science education in Israel and the United States. ACM Transactions on Computing Education, 14(2), 8.

Grover, S. (2015, April). "Systems of assessments" for deeper learning of computational thinking in K-12. Paper presented at the Annual Meeting of the American Educational Research Association. Chicago, April 15-20, 2015.

Grover, S., \& Pea, R. (2013). Computational thinking in K-12: A review of the state of the field. Educational Researcher, 42(1), $38-43$.

ISTE \& CSTA. (2014). Computational thinking for all. Retrieved Dec 1, 2017 from, https://www.iste.org/explore/Solutions/Computa tional-thinking-for-all

Jun, S., Han, S., Kim, H., \& Lee, W. (2014). Assessing the computational literacy of elementary students on a national level in Korea. Educational Assessment, Evaluation and Accountability, 26(4), 319-332.

Kafai, Y. B. (2016). From computational thinking to computational participation in K-12 education. Communications of the ACM, 59(8), 26-27.

Kong, S. C. (2016). A framework of curriculum design for computational thinking development in k-12 education. Journal of Computers in Education, 3(4), 377-394.

Lee, H. C., Lee, H. S., Sung J. S., Jung, S. W., Kim, S. H., Kim, S. H., et al. (2016). A study on surveying the actual conditions and evaluating the effectiveness of SW education in elementary and secondary schools. Seoul: Korea Foundation for the Advancement of Science and Creativity. Retrieved on August 26, 2017 from, https://www.ndsl.kr/ndsl/search/detail/report/reportSearch ResultDetail.do?cn=TRKO201600014678.

Lee, H. Y., \& Lee, T. W. (2015). Development of science subject program based on programming learning to improve computational thinking ability in middle school. Journal of the Korea Society of Computer and Information, 20(12), 181-188.

Lee, M. H., Tsai, C. C., \& Chai, C. S. (2012). A comparative study of Taiwan, Singapore, and China preservice teachers' epistemic beliefs. The Asia-Pacific Education Researcher, 21(3), 599-609.

Lin, T. J., Deng, F., Chai, C. S., \& Tsai, C. C. (2013). High school students' scientific epistemological beliefs, motivation in learning science, and their relationships: A comparative study within the Chinese culture. International Journal of Educational Development, 33(1), 37-47.

Liou, P. Y. (2014). Investigation of the big-fish-little-pond effect on students' self-concept of learning mathematics and science in Taiwan: Results from TIMSS 2011. The Asia-Pacific Education Researcher, 23(3), 769-778.

Liu, C. C., Cheng, Y. B., \& Huang, C. W. (2011). The effect of simulation games on the learning of computational problem solving. Computers \& Education, 57(3), 1907-1918.

Liu, C.-C., Chiang, S.-H., Chou, C.-Y., \& Chen, S.-Y. (2010). Knowledge exploration with concept association techniques. Online Information Review, 34(5), 786-805.

Lye, S. Y., \& Koh, J. H. L. (2014). Review on teaching and learning of computational thinking through programming: What is next for K-12? Computers in Human Behavior, 41, 51-61.

Manches, A., \& Plowman, L. (2017). Computing education in children's early years: A call for debate. British Journal of Educational Technology, 48(1), 191-201.

Mannila, L., Dagiene, V., Demo, B., Grgurina, N., Mirolo, C., Rolandsson, L., \& Settle, A. (2014, June). Computational thinking in K-9 education. In: Proceedings of the working group reports of the 2014 on innovation \& technology in computer science education conference (pp. 1-29). ACM.

Marginson, S., Tytler, R., Freeman, B., \& Roberts, K. (2013). STEM: Country comparisons: International comparisons of science, technology, engineering and mathematics (STEM) education. Final report. Retrieved August 26, 2017 from, https://dro.deakin.edu.au/eserv/DU:30059041/tytlerstemcountry-2013.pdf.

Ministry of Education, Taiwan (2016). Twelve year outline of the national fundamental education curriculum, elementary school, junior high school and high school. Retrieved on August 26, 2017 from https://www.naer.edu.tw/ezfiles/0/1000/attach/ 92/pta_10229_131308_94274.pdf.

Morony, S., Kleitman, S., Lee, Y. P., \& Stankov, L. (2013). Predicting achievement: Confidence vs self-efficacy, anxiety, and self-concept in Confucian and European countries. International Journal of Educational Research, 58, 79-96.

Nah, J. E. (2017). Analysis of computational thinking learning effect through learner observation. Korean Journal of General Education, 11(5), 349-378.

Park, R. K. E. (2016). Preparing students for South Korea's creative economy: The successes and challenges of education reform. Asia Pacific Foundation of Canada. Retrieved on August 26, 2017 from https://www.asiapacific.ca/sites/default/files/filefield/ south_korea_education_report_updated.pdf.

Román-González, M., Pérez-González, J. C., \& Jiménez-Fernández, C. (2016). Which cognitive abilities underlie computational thinking? Criterion validity of the Computational Thinking Test. Computers in Human Behavior, 30, 114.

Shin, S-B (2015) The improvement effectiveness of computational thinking through Scratch education. Journal of the Korea Society of Computer and Information, 20(11), 191-197. 
Van Laar, E., Van Deursen, A. J., Van Dijk, J. A., \& De Haan, J. (2017). The relation between 21st-century skills and digital skills: A systematic literature review. Computers in Human Behavior, 72, 577-588.

Voogt, J., Fisser, P., Good, J., Mishra, P., \& Yadav, A. (2015). Computational thinking in compulsory education: Towards an agenda for research and practice. Education and Information Technologies, 20(4), 715-728.

Werner, L., Denner, J., Campe, S., \& Kawamoto, D. C. (2012, February). The fairy performance assessment: measuring computational thinking in middle school. In: Proceedings of the 43rd ACM technical symposium on computer science education (pp. 215-220). ACM.

Wing, J. M. (2006). Computational thinking. Communications of the ACM, 49(3), 33-35.
Wong, G., Cheung, H. Y., Ching, E. C. C., \& Huen, J. M. H. (2016). School perceptions of coding education in K-12: A large scale quantitative study to inform innovative practices. In: Proceedings of 2015 IEEE international conference on teaching, assessment and learning for engineering (pp. 5-10). Piscataway, NJ: IEEE.

Wong, G., Ching, M., Tang, J. K. T., Zhang, L., Cheung, H. Y., \& Chui, H. L. (2015). Impact of computational thinking through coding in K-12 education: a pilot study in Hong Kong. In Proceedings of the 11th international conference on technology education in the Asia Pacific Region. Hong Kong: Hong Kong Polytechnic University.

Publisher's Note Springer Nature remains neutral with regard to jurisdictional claims in published maps and institutional affiliations. 